\title{
Generative design: information flow between genetic algorithm and parametric design in a steel structure construction
}

\author{
Design generative: o fluxo de informação entre algoritmo \\ genetico e design paramétrico na construção de uma \\ estrutura metálica
}

\section{Renato Godoi da Cruz \\ Cláudia Maria Arcipreste \\ Rafael Lemieszek Pinheiro (ii) \\ Rovadávia Aline de Jesus Ribas}

\section{Abstract

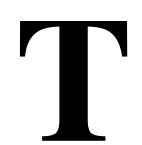

his paper describes the construction of an information flow that combines parametric modelling and genetic algorithms to optimise both the total weight of a structured steel roof and the shape of its surface to maximise the generation potential of photovoltaic energy. Through the systematisation of a design process using genetic algorithms integrated with generative design as an architectural design method, architects can work with problem parameterisation, going one step further than the mere formal proposition of solutions. As a result, we present a process in which there is a dialogical relationship between the architect and project in a continuous flow of information in the initial steps of the design process, guided by predefined optimisation objectives. Therefore, it is relevant to note that the designer accepts a reduced creative control over the final shape in favor of control over the core principles that constitute the optimisation algorithms. An approach that involved the designer in a process of post computational processing evaluations is also highlighted, giving him better support to discuss and analyze the design options.

Keywords: Generative design. Genetic algorithms. Structural optimisation. Environmental optimisation. Steel construction.

${ }^{1}$ Renato Godoi da Cruz ${ }^{1}$ Universidade Federal de Ouro Preto Ouro Preto - MG - Brasil

${ }^{2}$ Cláudia Maria Arcipreste ¿Universidade Federal de Ouro Preto Ouro Preto - MG - Brasil

${ }^{3}$ Rafael Lemieszek Pinheiro ${ }^{3}$ Universidade Federal de Minas Gerais Belo Horizonte - MG - Brasil

${ }^{4}$ Rovadávia Aline de Jesus Ribas ${ }^{4}$ Universidade Federal de Ouro Preto Ouro Preto - MG - Brasil

Recebido em 28/07/20 Aceito em 21/03/21

\section{Resumo}

Este artigo descreve a construção de um fluxo de informações que combina modelagem paramétrica e algoritmos genéticos para otimizar o peso total de uma cobertura de aço estruturada e a forma de sua superfície para maximizar o potencial de geração de energia fotovoltaica. Através da sistematização de um processo de design usando algoritmos genéticos integrados ao design generativo como método de projeto arquitetônico, os arquitetos podem trabalhar com a parametrização de problemas, indo um passo além da mera proposição formal de soluções. Como resultado, apresentamos um processo no qual existe uma relação dialógica entre o arquiteto e o projeto em um fluxo contínuo de informações nas etapas iniciais do processo de projeto, orientado por objetivos de otimização predefinidos. Portanto, é relevante notar que o arquiteto aceita um controle criativo reduzido sobre a forma final em favor do controle sobre os princípios centrais que constituem os algoritmos de otimização. Destaca-se também uma abordagem que envolveu o arquiteto em um processo de avaliação pós-processamento computacional, dando-lhe melhores subsídios para discutir e analisar as opções de projeto.

Palavras-chave: Design generativo. Algoritmos genéticos. Otimização estrutural. Otimização ambiental. Construção em aço. 


\section{Introduction}

Traditional design processes can be described as conscious experimentation processes: formal solution hypotheses are formulated, tested (in drawings and models) and discarded or adjusted until a designer is satisfied with the result. This means that there is a small number of hypotheses and a very limited number of iterations that the designer is able to consciously go through to optimise the initial design ideas. In this work, we propose using parametric tools to explore the maximum number of design hypotheses within a set of variables stipulated beforehand to explore complexities that manually would be, in practical terms, impossible to be tested.

We used Grasshopper, a node-based editor within the Rhinoceros modelling software that allows the creation of a series of geometric operations to produce a flexible geometry, based on input variables. These variables can be set as ranges rather than predefined values: the total horizontal span of the roof, for instance, should not be smaller than a certain value but could be larger, just as its minimum height at any given point. These two variables alone can result in countless shape possibilities, each one with different proportions, total weight, ideal shape and so on. As variables are added, the potential complexity of the roof structure increases exponentially.

To manage this complexity, these variables are controlled by a genetic algorithm that tests different values while aiming to optimise the model through minimising a single index: the division of the total steel cost of each design, expressed in Brazilian reais $(\mathrm{R} \$)$ by the total solar energy generation potential, also expressed in $\mathrm{R} \$$. This means that the algorithm will seek to reduce the design, but will be willing to make it bigger if the additional cost is more than offset by the extra savings generated by the solar panels.

Together, these two strategies provide an approach that ensures high performance by allowing the architect to act guided not only by the form itself, but also by a dialogical process of form generation, based on a set of constraints of physical, environmental and local factors that result in their optimisation.

In order to structure and conduct the work, specific objectives were defined: reviewing the theoretical and practical content related to the architectural design practice, addressing processes in which the architect gives up control of the specific definition of a solution in favour of exploring a greater variety of formal configurations than would be possible using traditional design processes; the application of this content in the initial stages of architectural design of metal construction, seeking the creative generation of the form based on predefined optimisation criteria of the solution, as well as the description of this procedure in order to contribute and support further works by architects and other professionals involved in design processes.

This paper presents, therefore, results of this experiment carried out during a master's degree research, combining parametric modelling and genetic algorithm strategies for the creative generation of shapes. The case study addresses the process of optimising parameters of a steel structure covering the stands (tiered rows of seats) of a football field. This membrane-coated roof also receives photovoltaic panels for power generation. We aim to present the process of developing a formal solution that would minimise the total weight of the structure and consequently its cost, while maximising the energy generation potential of the structure. Applying performance and structural optimisation criteria, fields of knowledge common to architecture, engineering and other disciplines - mathematics and computer sciences in a transdisciplinary articulation within a case study can be complemented and replicated in different scenarios.

\section{Theoretical references}

Architectural design processes depend on each choice made, whereby each decision defines a path that prevents different possibilities, unless the architect returns and objectively changes those decisions. Studies that have been the subject of debate for decades, such as those by Broadbent (1971), Alexander (1976), Schön (2000) and Lawson (2011), aim to make project practices explicit on rational grounds, exposing the existence of a "problematisation methodology". Decisions are made incrementally through a succession of design problem solving and the final design is usually the result of successive approximations. This occurs in processes of action, reflection on action and about the action, undertaken by the designer, mediated by drawings and other representational models (SCHÖN, 2000).

According to Lawson (2011), it is a path marked by cycles of analysis, synthesis and evaluation. The architect's competence for decision making is in his ability to retake, restructure, adapt and apply relevant ideas from previous projects (OXMAN, 2006; LAWSON, 2011). This can, however, be a problem when the architects' concepts become a pattern of thinking, and solutions to new issues can be restricted to the mere

272 Cruz, R. G. da; Arcipreste, C. M.; Pinheiro, R. L.; Ribas, R. A. de J. 
reproduction of previous solutions. This limits the progress of a given project in its sequential stages and impairs discovering innovative possibilities (BUCHANAN, 1992).

It must also be considered that in architectural design practices there is no single solution (answer) to a problem (question). Based on this recognition, Vassão (2010) proposes the project as a question, contradicting the understanding that it would be a definitive solution, or an answer to problems.

We will highlight two of the many aspects of the design process highlighted by Vassão. The first one is that every project is as complex as it is understood to be. This is because every object, or every process, is always part of a larger system. When approaching the project as a question, the architect may be mapping this system and not speculating on an answer that he/she individually assumes as the correct one.

The second aspect of the metadesign process is an ethical one. Treating a design process as a question, the designer partially assumes the position of an observer, which allows design solutions that are not within the designer's repertoire to emerge.

The experience presented here aims to apply the theoretical framework of design processes to a real-world example, delineating the limits between objective tools for design optimisation and the role of the designer while using these tools. We present a process whereby a structure with a predefined shape can be optimised but, beyond that, the predefined metrics can yield shapes that had not been anticipated by the designer.

\section{Design and control}

Different experiences exist where design professionals have adopted methods for the emergence of results that are structurally different from those obtained by conventional procedures, if not in their final products (answer), at least in the ways to reach them (questions). The experiments with suspended networks by Antoni Gaudí, the Optimised Path Systems study, by Frei Otto and the Oblique WTC, a project by Lars Spuybroek are examples that result from such methods (Figure 1).

These examples have two important characteristics. First of all, they are fluid processes that lead to continuously adjusted results according to changing conditions. Second, they are focused on processes, not finalised designs. In all three cases, the methods adopted search for different, more convenient ways to deal with the problem (question), as opposed to methods based on the direct search for a solution (answer).

According to Vassão (2010), the first characteristic refers to a customised application of scientific procedures (modelling) for the synthesis of form (final design). These design methodologies are opposed to the attempt to delimit a more general scientific basis (theorem). The second characteristic concerns control, or, more specifically, the lack of it in the design process. It can be observed that in all three cases, architects partially lost control of specific solution definitions to operate directly in the formalisation of problems.

To illustrate this approach, we will review some examples from two perspectives. First, recognising architecture as a highly complex system, where the number of variables in the project (controlled system) is exponentially greater than the number of variables that the architect (controlling system) can anticipate. This is traditionally dealt with by adopting restrictions or eliminating certain branches of possibilities, rather than by promoting effective management of the process (VASSÃO, 2010).

This is because, according to Ashby (1970), for one system to be able to regulate another, it is required that it has at least as many states as the system that one wishes to control.

\section{Figure 1 - Diagrams of the methods proposed by Gaudi, Frei Otto and Lars Suybroek}

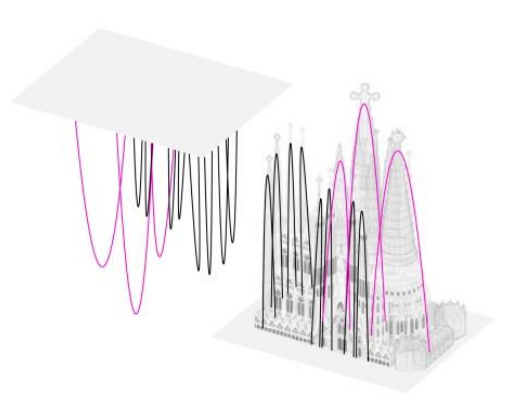

gaudí
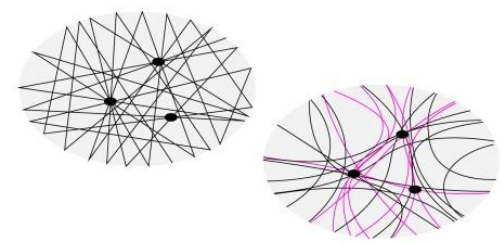

otto

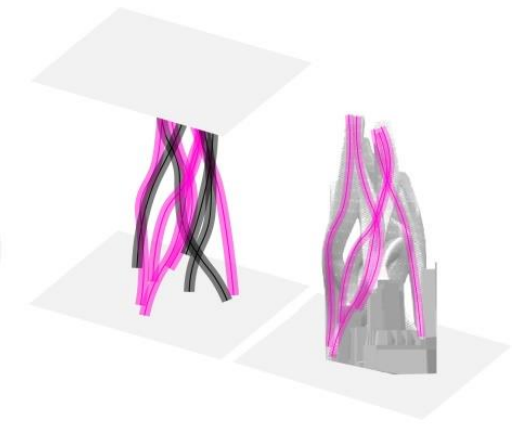

spuybroek 
In the context of architectural design this type of management is present in project processes based on the solution, that is, those in which the architect designs the final product from his/her own previous knowledge and instinct. In such cases, the probability of discovering a novel design solution is slim (LAWSON, 2011).

According to Glanville (2002), giving up control (that is, direct control over the final design) can expand the number of possibilities, allowing the emergence of unforeseen options. To do this, the author suggests a reformulation of how we understand the value of control. to allow us the benefit of being out of control.

The absence of control, in this case, can be used to discover innovative alternatives that would otherwise be ignored or not even tried by the architect in his/her design process. Giving up control in design practice is not accepting a smaller or incomplete design, but to open up possibilities for the novel - the architect still curates and adjusts the final design as needed.

What does it mean, then, to give up control in the practice of architectural design? According to Nagy (2018), a good strategy can be seen in the way organisms are projected in nature.

\section{The project as control}

One should not understand the way organisms emerge in nature as "design" in its intentional sense, as is traditionally the case in architecture. The sense of design used by Nagy (2018), in this case, is in the way that nature responds to the process that determines formal characteristics of a species when influenced by the environment over a given time.

First described by Charles Darwin, this process operates at a level of properties and abilities that all members of a species share with each other. A fundamental characteristic of a species is its ability to reproduce, since, over time, this process continuously improves species through adaptation and interaction, in a process known as natural selection.

According to Nagy (2018), even though we do not yet have the tools and knowledge necessary to design totally natural systems, mathematical concepts provide us with a concrete way to reformulate the evolutionary process as fundamentally an optimisation process.

Most optimisation problems, according to Yang (2010), can be described in genetic form (Equations 1 to 3):

$\frac{\frac{\min }{\max }}{x \in R^{n}} f_{i}(x),(i=1,2, \ldots, M)$

subject to $h_{j}(x)=0,(j=1,2, \ldots, J)$

$g_{k}(x) \leq 0,(k=1,2, \ldots, k)$ Eq. 3

Where $f_{i}(x) ; h_{j}(x)$ and $g_{k}(x)$ are functions of the vector (Equation 4 ):

$x=\left(x_{1}, x_{2}, \ldots, x_{n}\right)^{T}$

The components $\mathrm{xi}$ and $\mathrm{x}$ are called design variables. The $f_{i}(x)$ functions where $i=1,2, \ldots, M$ are called objective functions. We can classify the optimisation as mono-objective, when $M=1$, or multi-objective, when $M>1$. The space reached by the decision variables is commonly called the project space $R^{n}$, while the space formed by the values of the objective function is called the solution space and the equalities $h_{j}$ and inequalities $g_{k}$ are called constraints (YANG, 2010).

Optimisation problems can be operated by different approaches, the most common being the use of algorithms. For this paper, the Genetic Algorithm (GA) was chosen. This algorithm is particularly interesting because its rules and operations are inspired by Darwinian evolution and the natural selection of systems found in nature (SHIFFMAN, 2012), which allows us to explore the design process in architecture using the potentialities of natural systems.

In Computer Science, GA refers to the technique of seeking a specific result by outlining a set of problems. In the context of architectural design, one of the methods that uses this type of algorithm is called Generative Design. Its purpose is to explore, in an agile and effective way, new possibilities of answers within a universe of questions.

In our experiment, a hybrid form of design emerges from the partial manipulation of final objectives of the structure, rather than rationally designed shapes to address objectively perceived preconditions of the design.

274 Cruz, R. G. da; Arcipreste, C. M.; Pinheiro, R. L.; Ribas, R. A. de J. 


\section{Design of design}

To design like nature, we need to consider how we can design a species (NAGY, 2018) and a fundamental reference of natural design system in this paper is its relationship between genotype and phenotype. The two are deeply interlinked, the phenotype of an organism being the product of the interaction of a genotype with its environment. The biological process that causes an organism to develop and result in the phenotype is called morphogenesis.

In architecture, models of changeable geometries can be specially built using parametric modelling software. In parametric modelling, projects are no longer designed, but programmed based on geometric and mathematical relationships. This allows the construction of mutable designs, making it possible to design like nature (Figure 2), as it broadens the definition of project as an individual - non-mutable project - to project as a system - one that encodes a whole species - within the design concept based on nature described by Nagy (2018).

In this perspective, the process of evolution of nature, because of its emphasis on performance, is an inspiration for our design process.

This approach is not something new and has been explored since the beginning of the development of the computational design field. This can be observed by the Digital Design in the Architecture map, prepared by Savov (2020) using data from 12,000 articles published between 1975 and 2019 (Figure 3). From these, 1243 have keywords such as computational design, form-finding, adaptive simulation, generative, performance, simulation, algorithm, optimisation and other related terms. This represents $10 \%$ of the works produced in this period.

On the other hand, Calixto and Celani (2015) present 22 years (1992-2014) of work with exclusively evolutionary approaches applied to spatial planning problems, concluding that the development of computing in this period has not yet significantly impacted the development of spatial planning problems, and is mostly theoretical and unapplied.

Recently, other authors have explored practical performance-based optimisation applications. Borges, Grilo and Fakury (2016), Leitão, Branco and Cardoso (2017) and Caetano et al. (2020) showed applications of structural optimisations but limited their application only to the optimisation of shapes or in their generations.

Barczik and Kruse (2016) and Nagy, Zhao and Benjamin (2018) presented hybrid generative approaches that yield high performance while allowing the designer to explore their results. Their approaches, however, lack the parameters with which to evaluate resulting designs.

Figure 2 - Genotype and phenotypes in the design approach

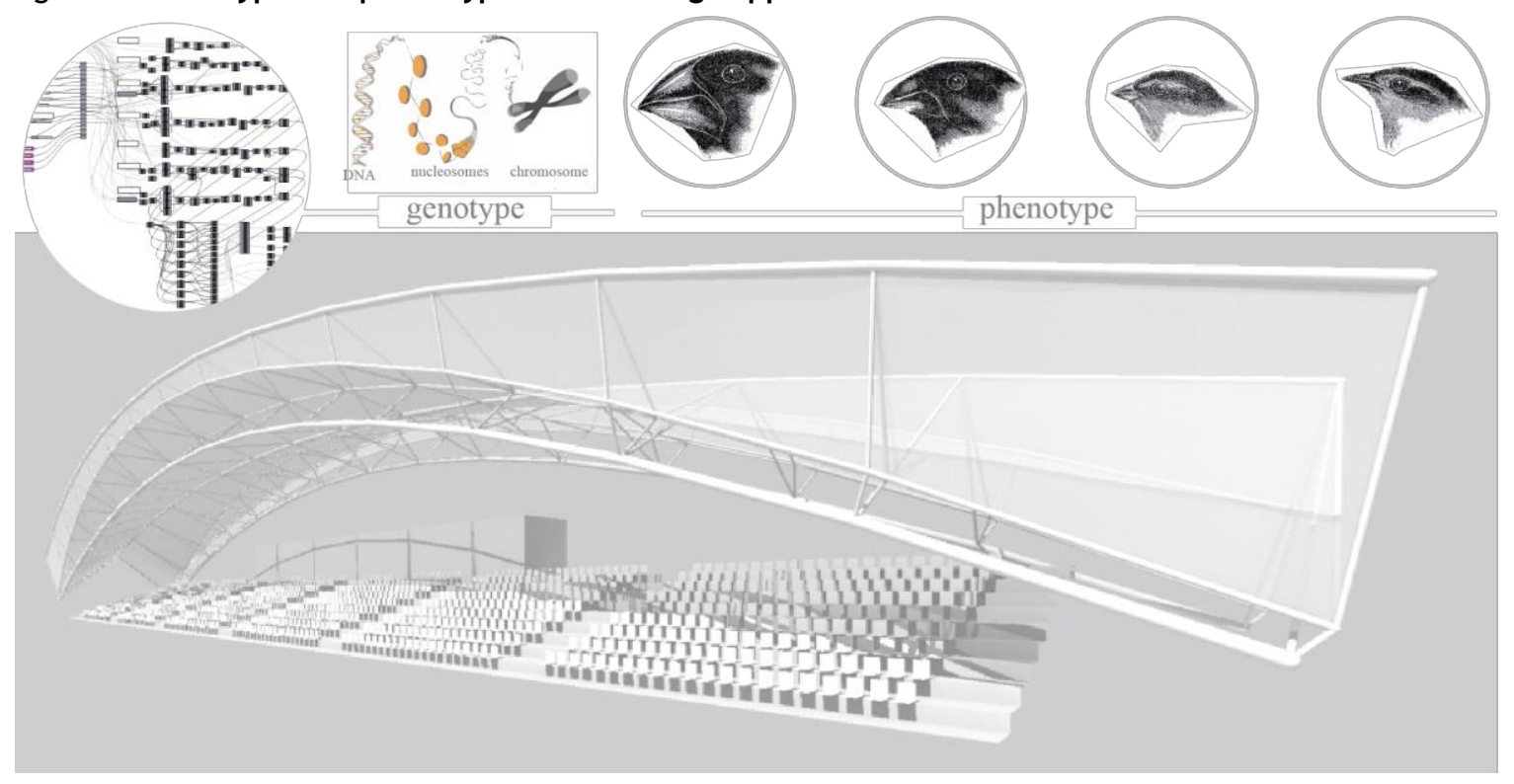


Figure 3 -Digital Design in Architecture Map

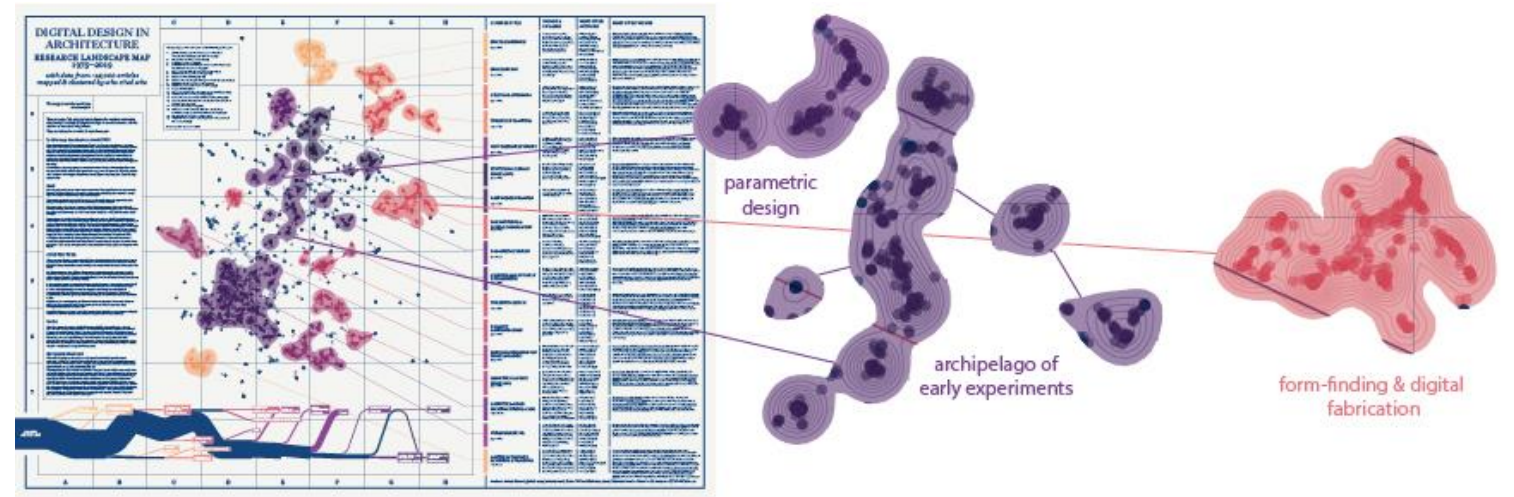

Source: adapted from Savov (2020).

This paper aims to go one step further. To do this, we suggest a post-generative approach to form (computational stage) where the architect focuses on evaluating results including new points of view, different from those taken as objectives in the search for formal solutions considered optimal. This strategy, added to that of using parametric tools and genetic algorithm to investigate the maximum number of design hypotheses from a set of variables previously stipulated, aims to contribute to the understanding of the generative project, not as an end, but as a means of helping this professional make decisions.

\section{Method and strategy for generative design}

In the experiment hereby presented, we applied the evolutionary process combining parametric modelling and genetic algorithm strategies to optimise the development of a steel structure of the roof of the stands (tiered rows of seats) in a soccer field. We organised the experiment in three stages according to the diagram presented in Figure 4. The first is the construction of the design space, that is, the system that generates all possible solutions for a given design problem. Then, for the first option, we created a mono-objective function to evaluate the performance of each design, seeking the minimum value possible for the net present value (NPV) of the costs of the structure considering both its construction cost and the market value of the energy produced by its solar panels; for the second option, we addressed it as a multi-objective problem, dividing the functions into different objectives: to minimise the total weight of the structure and to maximise the energy potential of the roof. Finally, the application of evolutionary algorithms to research the project space and find the highest performing design options in each case.

Rhinoceros software and its Grasshopper plug-in for parametric modelling were used. Grasshopper add-ons were also applied:

(a) Karamba - application for structural analysis;

(b) Ladybug - application for environmental analysis; and

(c) Discover - framework for generative design.

Then, a quantitative analysis of the data obtained was performed, using scatter plots and the selection of the best individuals (designs).

\section{Geometry: building the design space}

Figure 5 describes all the elements and their respective input parameters used to construct the model, which started with a set of parabolic arches subdivided and interconnected by diagonals. The first two parabolas (blue lines) are controlled by input parameters at the midpoint ( $\mathrm{z}$ axis). As they form the basis of the structure, these arches are supported at their ends. Then, four other parabolas (pink lines) are controlled by input parameters at the midpoint ( $\mathrm{z}$ and $\mathrm{y}$ axes) and at their ends ( $\mathrm{x}$ and $\mathrm{z}$ axis).

The last three parabolas, (green lines), are controlled by input parameters at the midpoint (z axis) and at the ends ( $\mathrm{x}$ and $\mathrm{z}$ axes). This set of arches, in turn, is controlled by an input parameter (division) and interconnected at their points by diagonals (grey lines). Finally, each set of members is controlled by an input parameter that allows us to define, independently, the dimensions of the tubular section of each type of 
member (A, B, C and D). This was done from a table with the 30 circular tubular sections most produced by the manufacturer Vallourec.

Figure 4 - Diagram of the generative process application

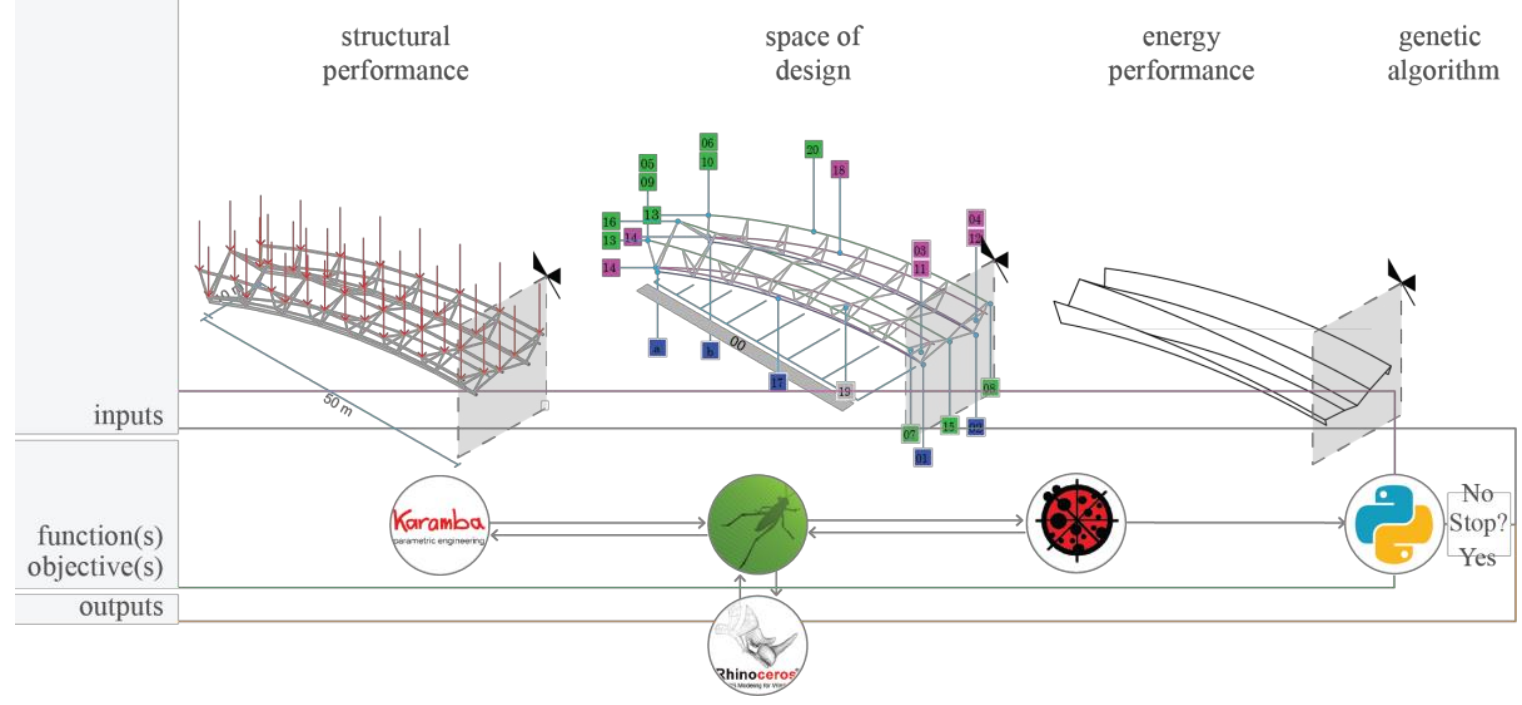

Figure 5 - Model diagram and parametric controls

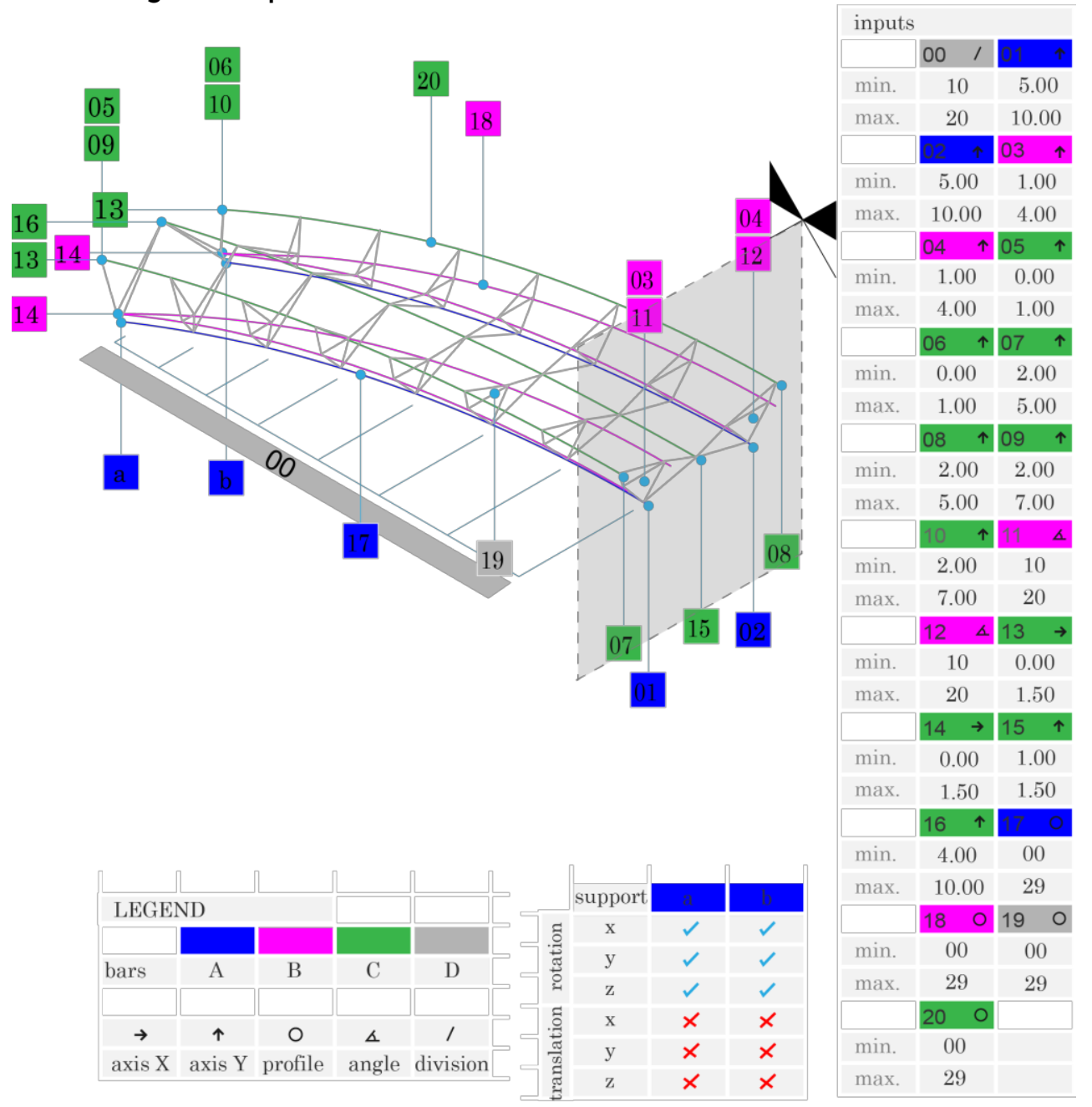


The design space of this model has 21 entries with values ranging from 10 to 500 characters.

Each combination of these inputs specifies a point within the project space that represents a project. Although the possible complexity is not immediately apparent, the total possible solutions for this project space is $2.21 \times 10^{42}$.

The manual test of each hypothesis is virtually impossible, since, considering the average hypothetical expenditure of 10 minutes per hypothesis, it would be necessary to dedicate $1.76 \times 10^{25}$ times the age of planet Earth, considering its age estimated at $4.54 \times 10^{9}$ years (SHIFFMAN, 2012).

In the analogy to the evolutionary process mentioned earlier, the results of the mutable model developed would be the phenotypes of the "roof structure" species while the set of input parameters that define the models would represent their genotype, that is, the set of chromosomes that describes all the formal possibilities of this organism.

\section{Building the structural assessment}

To apply the genetic algorithm in the search for high performance designs, the model must also contain a set of measures that inform the algorithm whose designs have the best performance. The structural analysis is a fundamental step in the elaboration of this system.

In order to obtain the structure's response to the actions that are applied to the model, we used Karamba, an add-on that calculates the displacements and the soliciting efforts in the model elements built in the Grasshopper environment.

For the structural model of Karamba, based on the Finite Element Method, the element of circular tubular sections was used for all elements. After assembling the structural model, Karamba offers, in real time, feedback on the calculations of displacements and efforts during changes in the dimensions and strength of the material in the structure model (PREISINGER, 2016).

In the configuration of the supports, freedom was allowed for all degrees of movement in the rotation axes $(\mathrm{Rx}, \mathrm{Ry}, \mathrm{Rz})$ and restriction for all degrees of freedom in the translation axes (Tx, Ty, Tz).

The definition of loads was divided into the structure's own weight, wind load and permanent loads. To define these loads, the following combinations were considered (Equations 5 to 8):

$\operatorname{comb}_{01}=1.4 x C P+1.4 x C A$

$\mathrm{comb}_{01}=1.4 C P+1.4 x C A+1.4 x 0.6 x \mathrm{CV}$

Eq. 6

$\mathrm{comb}_{01}=1.4 x \mathrm{CP}+1.4 x \mathrm{CV}+1.4 x 0.7 x \mathrm{CV}$

Eq. 7

$\mathrm{Comb}_{01}=1.4 x C P+1.4 x \mathrm{CV}$

Eq. 8

$\mathrm{CP}$ is the permanent load, AC the accidental load and CV the wind load. To determine part of the permanent loads, the area of the membrane cover was calculated beforehand. The area reserved for photovoltaic panels was also calculated, a construction presented in the next section. The permanent and overload loads were distributed over the nodes of elements D.

To define the wind load (CV), two points were considered: it is not simple to determine the wind load in buildings that are not rectangular and gabled; this experiment is an optimisation process and therefore needs to incorporate calculations that are dynamic.

From this, a series of simplifications were made to determine the wind load. The first was to calculate the drag force $(\mathrm{Fa})$ only at $90^{\circ}$, which corresponds to the longest length of the structure and the most orthogonal side. The other simplification was to determine an average height for the entire model.

The idea of assigning a single point for height made the construction of the algorithm easier and the optimisation work more agile, because every time the geometry changes during the optimisation process, the drag force $(\mathrm{Fa})$ can be recalculated instantly and the midpoint refers to the area (Ae) where the wind acts, which in this case is not a regular and constant geometry (it changes throughout the optimisation process).

As the results obtained in the structural analysis directly influence the feasibility of the project, we define the following conditions: dimensioning in the ultimate limit state of the bars subjected to the efforts of compression, traction and bending moments, in which these calculating efforts must be equal to or less than that these same resistant efforts of calculation; determination of the maximum displacement of the structure, where the maximum permitted arrow must be less than the largest span divided by three hundred $(1 / 300)$.

278 Cruz, R. G. da; Arcipreste, C. M.; Pinheiro, R. L.; Ribas, R. A. de J. 
These limits are based on Brazilian standards (including NBR 6123 (ABNT, 1988), NBR 8681 (ABNT, 2003) and NBR 8800 (ABNT, 2008)).

For dimensioning in the ultimate limit state, the actions of active requests were increased (multiplied by 1.10) and those of resistance, in turn, reduced (divided by 1.10) (Equation 9):

$S_{d} * 1.10 \leq \frac{R_{d}}{1} .10$

The treatment adopted to deal with the conditions of restrictions in this work was punitive, that is, those options that broke the restrictions rules were immediately disqualified, which prevented them from participating in the next intersections (YENIAY, 2005).

The penalty method was constructed in two ways. First in multiplicative form (Equation 10):

$\operatorname{eval}(x)=\left\{\frac{f(x),}{f(x) p(x),}\right.$

Under this convention, the objective was the result of eval(x), where $\mathrm{p}(\mathrm{x})$ represents a penalty term in the structural verification logic. If no violation occurred, $\mathrm{p}(\mathrm{x})$ would equal zero. Otherwise, the option would be disqualified, giving $\mathrm{p}(\mathrm{x})$ equal to one hundred thousand $(100,000)$. This logic was applied in the evaluation of the compression, traction and bending moment analyses.

The second way occurs in the form of addition. This convention was applied exclusively to the displacement criterion (Equation 11):

$\operatorname{eval}(x)=\left\{\frac{f(x),}{f(x) p(x),}, \quad\right.$ if $x \in F$

Although they do not describe the relative performance among design options, constraints are important because they determine whether an option is viable or not. In our analogy to the evolutionary processes found in nature, the restrictions functioned as a survival test for individuals (project options).

\section{Building energy assessment}

Once the conditions for structural integrity were parametrised, we were able to add other objectives (problems), such as the maximisation of the energy potential of the roof based on the example of Spasic (2015).

This objective was built with components of the environmental analysis plug-in Ladybug, which allows us to import and analyse meteorological data in the Grasshopper environment.

The configurations of the photovoltaic model from the California Energy Commission (CEC) Modules library were imported to calculate the amount of electrical energy that can be produced by the surface. The module chosen for this phase was the Centrosolar America VS-160C1 cell, version NRELv1, considering its flexibility and low weight. This setting calculates the amount of electrical energy that can be produced by the roof surface based on the NREL PVWatts v1 calculator.

\section{Genetic algorithm: the Discover evolutionary solver}

For an effective search for high performance options, we needed an external system that could work with the model. The meta-heuristic algorithms proved to be particularly interesting because their rules and operations are inspired by the evolutionary processes of nature, which would allow us to explore design in a manner similar to what occurs in natural design (SHIFFMAN, 2012; NAGY, 2018).

Discover, by Nagy, is a flexible and modular structure user to explore the design space based on this type of algorithm. Discover consists of a modular library for single-objective and multi-objective optimisation, written in Python, and an interface written in JavaScript that allows the user to visually explore the optimisation process.

Although Discover is a good tool for solving complex design optimisation problems, the algorithm is driven by only four basic operators, based on natural selection:

(a) generation - the algorithm randomly generates a sample of the design space alternatives, forming the initial generation;

(b) selection - the algorithm selects the best positioned individuals to be used in the next generation, thus creating a "mating pool" containing the best designs, according to its objective; 
(c) crossing - the algorithms selected as promising designs are recombined to create a new population of designs; and

(d) mutation - ensures that the search explores solutions not contained in past generations through pseudorandom variation.

This path is similar to that of natural evolution. In both, the genetic information of the parents is randomly recombined to create a new individual. The basic idea is that since the parents have survived long enough to reproduce, both must have some genetic material that could be useful for the survival of the species in general. When recombining, the new individual will probably inherit winning characteristics from both parents - a convergence factor, increasing their chances of surviving and reproducing in a next generation (WIRSANSKY, 2020).

These methods alone, however, might not find the best possible solution. This happens when the alternatives of the first generation, carried out randomly, have no or few fundamental characteristics in their genetics, preventing the transfer of important information to the new generation. Therefore, as in nature, we need a mechanism that can randomly insert new information into the genetic background. This is done by the mutation operator, responsible for changing the entries of a random number of children, usually a small percentage, before entering the next generation - a factor that stimulates diversity (WIRSANSKY, 2020).

\section{Configuring the genetic algorithm}

This part involved running a template available as part of the Discover package in a Python interface. Figure 6 shows the complete model.

In this model, all input parameters (line 05) have been configured. In this same file, the output parameters were also established (line 27). In these lines, the objective functions of the experiment are defined.

In the first stage of the experiment, we were interested in problems with only one objective function, that is, those described as mono-objective. Thus, a composite function was constructed that should minimise the result between dividing the product of multiplication between the total weight of the structure (in $\mathrm{kg}$ ) and the average price of steel (in $R \$$ ) by the product of the multiplication between potential energy (in $k W h$ ) and the average price of $k W h$ (in $R \$$ ).

For the second phase, the total weight of the structure and the energy potential of the roof were divided into different objective functions, creating a multiobjective problem: minimising the total weight of the structure and maximising the energy potential of the roof (line 28).

\section{Figure 6 - Python definition of the genetic algorithm for generative design}

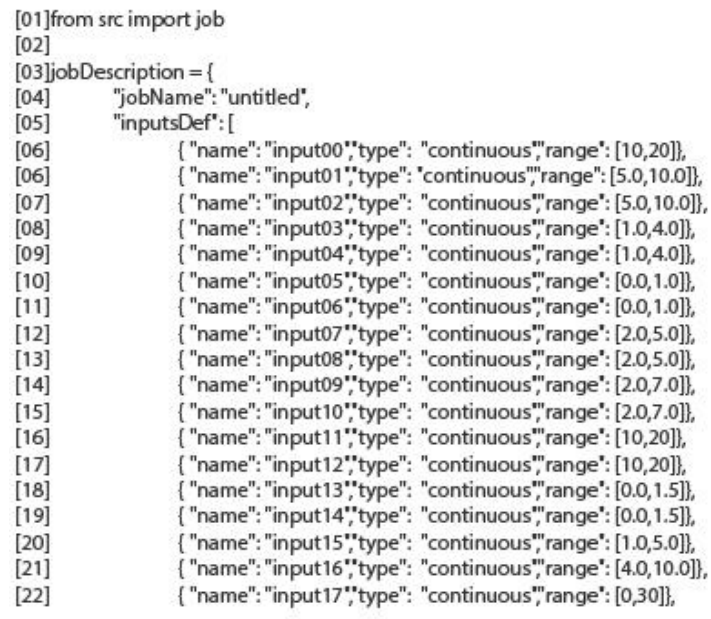

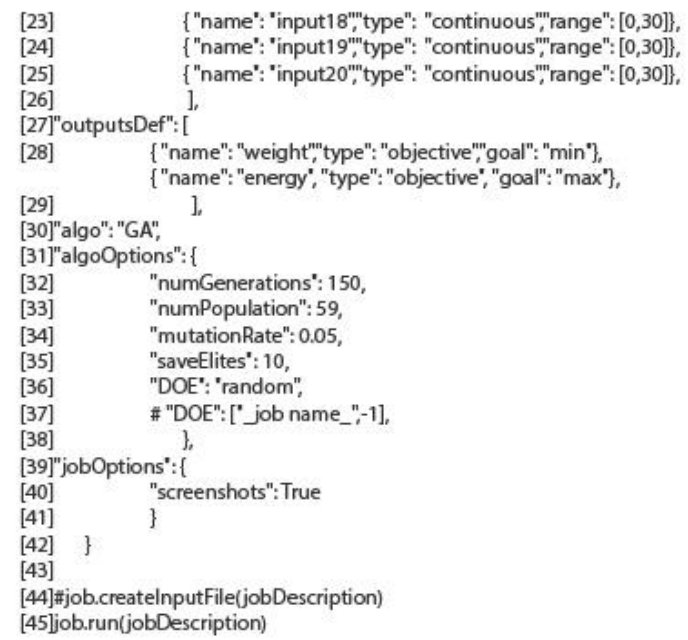


Once the input and output parameters were defined, the necessary options for the general work were concluded as follows:

(a) number of generations: 150 (line 32);

(b) population number: 59 (line 33);

(c) mutation rate: 0.05 (line 34); and

(d) elite number saved: 10 (line 35).

After filling in the model, the algorithm was executed (line 45).

When the optimisation was completed, the Discover package offered a file containing the database of each option explored in the project space during the optimisation. This file contained the information for each project, with all its inputs and outputs. Finally, a .html file was also made available, which is used to launch the Explorer interface. This interface was adopted, making it possible to visualise the results and plot them in relation to the objectives, in a scatter plot. The results are discussed below.

\section{Analysis of results: the project's}

The experiments generated a set of 11,800 different project options, 5,900 alternatives in each stage, which were analysed in search of an assertive answer (solution) for the project. At the outset, an important limitation of the process was perceived, since with each decision made, a large part of the space for exploring possibilities was restricted in the later phases, considerably reducing the probability of reaching a truly "optimal" project.

The implementation of this strategy has made it possible to give up control of the specific definition of a solution in favour of exploring a greater variety of options than would be possible using traditional design methods.

In the experiments presented, the loss of control was due to the mathematical modelling of the problem and the automatic search for solutions using heuristics. This loss of control stems from the fact that the final shape of the structure was not subjectively imagined by the designer but reached through processes that likely results in shapes at least somewhat different to what could have been imagined beforehand. In the next sections, a detailed analysis of the optimisation experiments will be presented through a quantitative approach to the data obtained, through scatter plots and strategies for selecting the best individuals (design options) in each case.

\section{Experiment 01: mono-objective optimisation}

In the first stage, a set of 5,900 options was generated. The task at this stage was to filter the data sets by scores and select the alternative with the best performance.

Figure 7a shows the scatter plot of the project space searched by Discover. Each circle represents a project.

We emphasise that, as it is a mono-objective optimisation, the graph presents all the options aligned as the abscissa and the ordinate assume the same value (goal). This makes its interpretation very intuitive because the lower the weight of the project, the closer to the bottom left corner it will be.

In this graph, the evolutionary process described above can be observed. We noticed that with the crossing of the intersections, the designs were progressively pushed to the lower left corner of the graph (optimal point). For the sake of comparison, some options were shown (Figure 7b).

Created in the first generation, option \#6 is the worst. This is because, at this stage, the alternatives are completely random and, therefore, individuals may contain few right components to achieve the goal. For this reason, this option failed in more than one criterion in the structural analysis and was pushed to the opposite end of the optimal point. They can be clearly seen in Figure 8.

We noticed that, even in the random phase, options \#11, \#21, \#22 and \#28 show progressive improvements. From these, option \#28 came very close to the optimum, even close to individual \#5603 of the last generations, presenting the greatest potential for future crossing, when compared to the other options mentioned. 
Figure 7 - Mono-objective scatterplot (a) and chosen options (b)
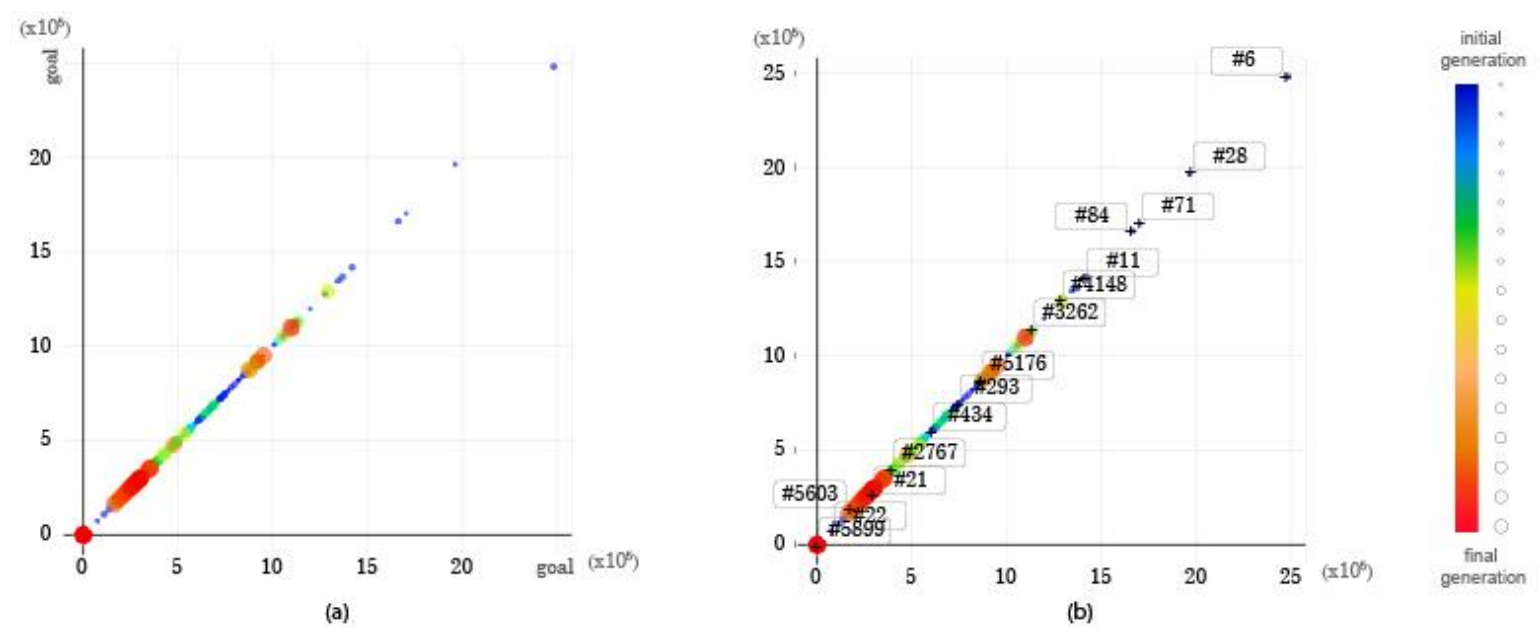

Figure 8 - Project progress on the mono-objective scatterplot

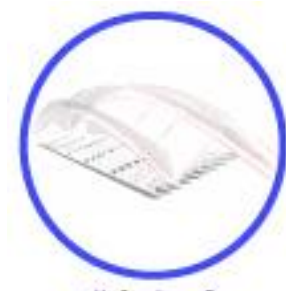

\# degign 6

2483355

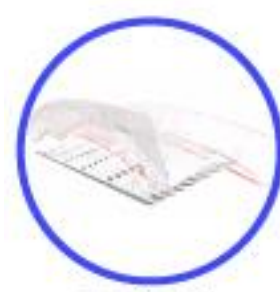

\# design 71

1704756

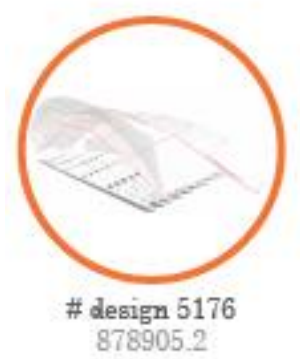

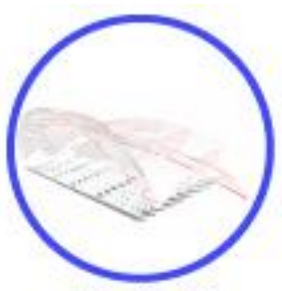

\# design 11

1420456
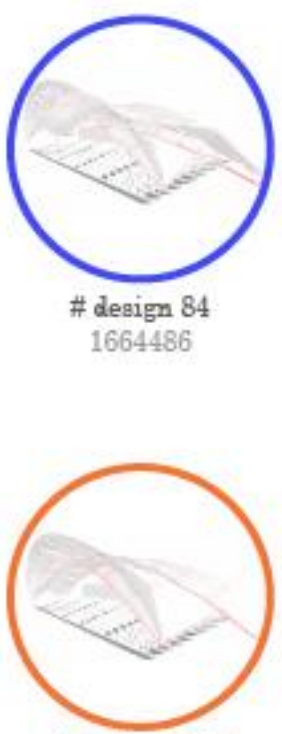

\# design 5603

10.0
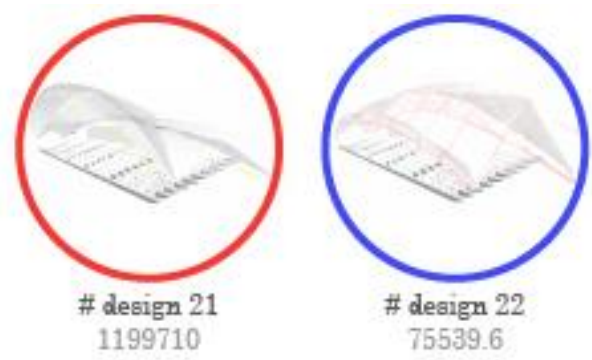

\# deaign 22

75539.6
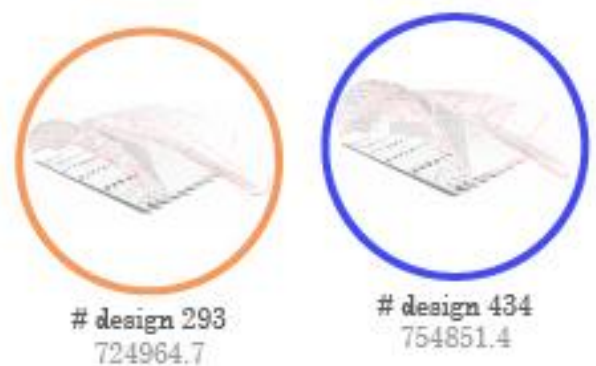

\# design 434

754851.4
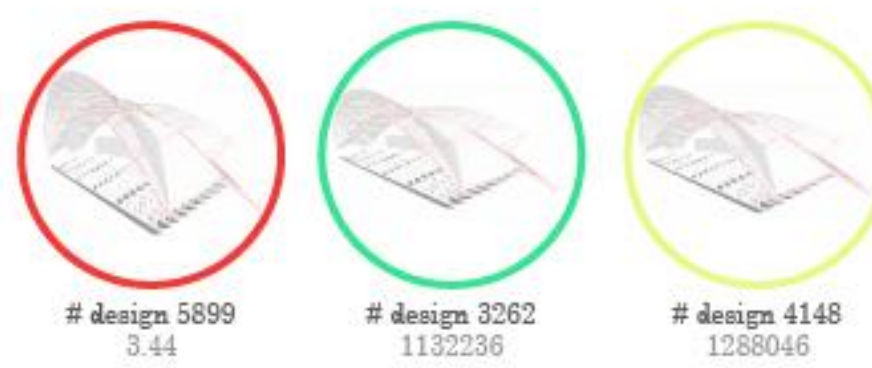

Alternatives \#71, \#84, \#293, \#434, \#267, \#3262, \#4146, \#5176 show, in turn, that despite the progress of the process, the intense crossing still generates bad individuals, which were possibly discarded.

In this case, option \#5899 can be considered ideal. This is because there is no other that has a final "goal" parameter smaller than 3.44 . 
When accessing this option in the viewer provided by the Discover package, we have access to all parameters of inputs and outputs of this model, such as the profile sections (Figure 9), the value of its objective, among others.

In Figure 10, this alternative can be seen enlarged and it is defined by its input and output parameters.

\section{Experiment 02: multiobjective optimisation}

Figure 11a shows the scatter plot of the second stage of the experiment with 5,900 alternatives. The objective of this step was to find options that met the structural constraint with the minimum weight (objective weight) and the greatest possible energy potential (objective energy). Given that these two objectives are in competition, there is no single solution, as presented in the previous experience, but, rather, a set with several solutions considered satisfactory, which allows the decision on the choice of solution to occur after the computational process.

Isolating the high-performance alternatives in the project space, we notice that the drawings form a line that moves from the bottom left corner upwards. This is because the strategy adopted as a constraint moved them to this position.

In this case, in which the negotiation between having more coverage area contradicts the criterion of less weight, the options considered optimal were concentrated in a line perpendicular to the abscissa (minimised objective) and parallel to the ordered (maximised objective).

The options along this line can be considered optimal. This is because improving any of them in one objective would necessarily make it worse in another. Thus, a thorough analysis of several alternatives is necessary. For the sake of demonstration, we selected some of these options (Figure 11b) for a more detailed approach.

Figure 9 - Project option profiles \#5899
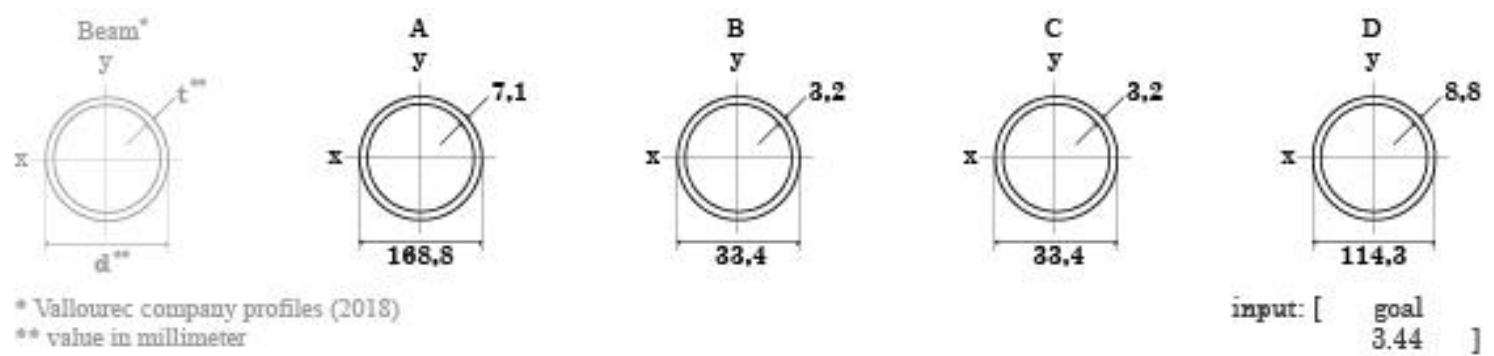

** value in millimeter

\section{Figure 10 - Design option \#5899}

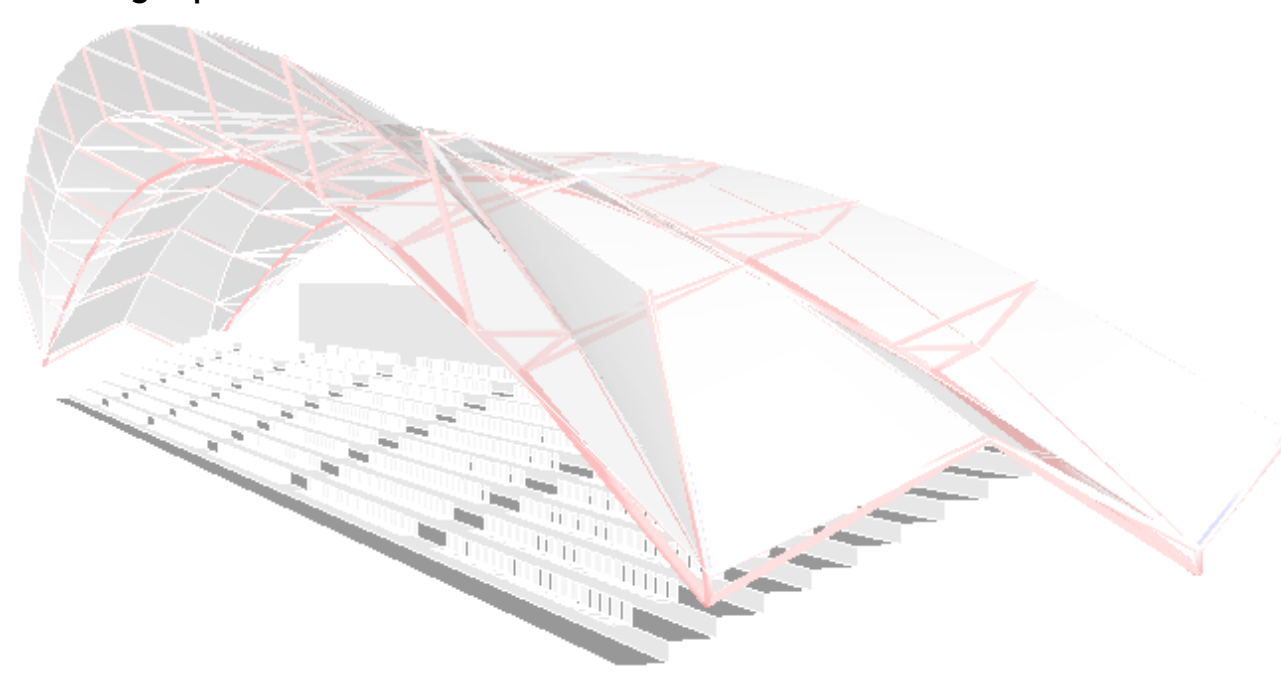


Figure 11 - Multi-objective scatter plot (a) and selection of part of the optimal options (b)

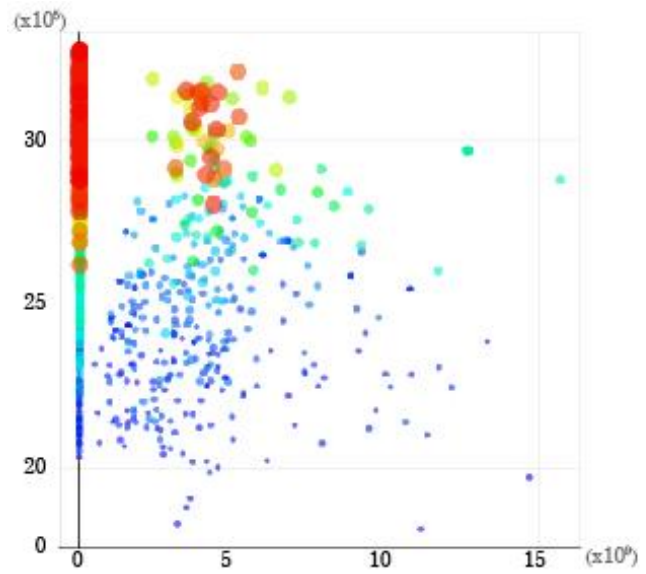

(a)

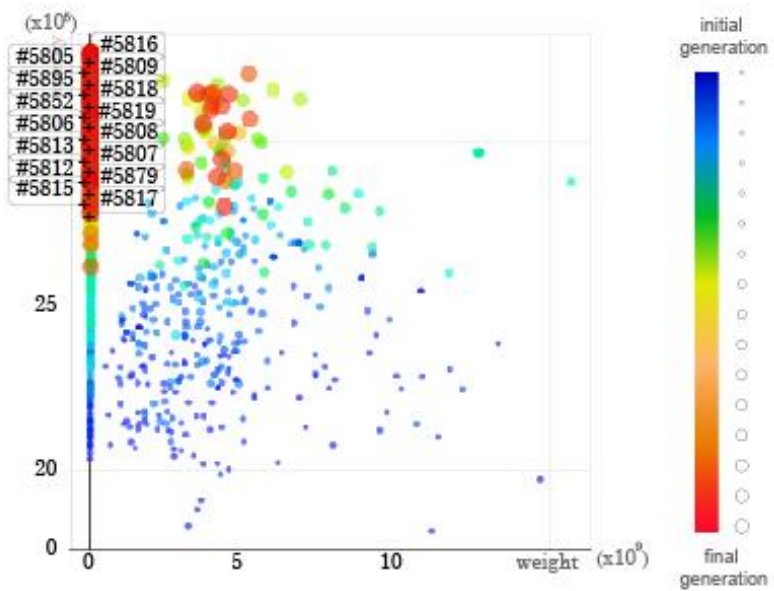

(b)

Once this set of options is selected, the task is then to discuss them. Here, the project is emphasised once again as a process, an open entity, where the participation of the architect and others involved, directly and indirectly, with the space to be built is fundamental for decision making, taking advantage of a correct exploration characteristic of each of the alternatives considered optimal. This approach consists of a dialogue between generative (computational) design and the conscious intervention of a designer focusing on evaluating the results and objectively picking the optimal choice. This is what differentiates the approach adopted in this work from the traditional design processes: the quality of the discussion and analysis carried out to subjectively achieve a final project is supported by a set of optimised solutions mathematically obtained through computational processes.

As an example of this task, let us imagine a direct relationship of the energy potential as an initiative to pay the total cost of steel, in weight, used to construct the roof (Table 1).

We have that option \#5852 is, in this case, the best choice. Accessing this option, we observe its input and output parameters. Figure 12 shows the profile sections for this option.

In Figure 13, this alternative can be seen enlarged and it is defined by its input and output parameters.

However, this logic changes when there is long-term planning, such as the reduction of energy consumption expenditures over 30 years.

In this new perspective, option \#5808 is the best choice. Accessing this option, the profile sections of this option can be seen (Figure 14).

In Figure 15, this alternative can be seen enlarged and it is defined by its input and output parameters.

\section{Final considerations}

The experiments presented highlight the relationship between optimisation and open design, where the designer reduces his objective control over the final shape as he takes up action upon the physical constraints that generate the shape. This loss of control is due precisely to mathematical modelling, which constitutes an analytical practice, and to the automatic search for solutions through heuristics. It also highlights the advantage of using the multiobjective methods compared to the mono-objective ones as it allows decisions to choose the solution to occur after the computational process. In addition to evaluating the results, the designer can add new points of view to these, different from those considered in the search for optimal solutions. It is a process that forms a continuous and expanding feedback loop in which the insertion of other optimisation parameters can occur in several stages, not ending in the initial design phases when the initial form generation occurs.

Thus, this work aims to contribute to the studies in the area from the perspective of generative design as a means, especially useful in the initial phases of the design process, and not as an end of the design processes in architecture, as the theme has been commonly treated. 
Table 1 - Comparative table

\begin{tabular}{|c|c|c|c|c|}
\hline ID & Cost $(R \$)^{1}$ & kWh $(\mathrm{R} \$)^{2}$ & Months $^{3}$ & 30 years $(R \$)^{4}$ \\
\hline \#5816 & $1.131 .123,60$ & $191.691,60$ & 82 & $4.437 .626,18$ \\
\hline \#5815 & $832.881,80$ & $168.751,52$ & 59 & $4.229 .663,89$ \\
\hline \#5812 & $917.966,20$ & $186.582,41$ & 59 & $4.679 .506,14$ \\
\hline \#5817 & $849.987,20$ & $169.891,02$ & 60 & $4.246 .806,02$ \\
\hline \#5879 & $854.774,20$ & $174.691,02$ & 59 & $4.385 .956,52$ \\
\hline \#5813 & $887.208,20$ & $177.774,36$ & 60 & $4.446 .022,56$ \\
\hline \#5807 & $863.828,20$ & $175.906,23$ & 59 & $4.413 .358,74$ \\
\hline \#5806 & $867,504.20$ & $176,626.07$ & 59 & $4,420,357.92$ \\
\hline \#5808 & $955,103.00$ & $190,987.90$ & 60 & $4,774,534.15$ \\
\hline \#5852 & $864,733.60$ & $185,764.66$ & 56 & $4,708,206.25$ \\
\hline \#5819 & $893,495.00$ & $181,131.24$ & 59 & $4,540,442.07$ \\
\hline \#5895 & $952,516.80$ & $177,529.29$ & 64 & $4,373,361.79$ \\
\hline \#5818 & $893,663.00$ & $184,690.57$ & 58 & $4,647,054.07$ \\
\hline \#5805 & $918,301.20$ & $188,541.29$ & 58 & $4,737,937.47$ \\
\hline \#5809 & $955,103.00$ & $190,987.85$ & 60 & $4,774,532.39$ \\
\hline
\end{tabular}

Note:

${ }^{1}$ total structure cost $=$ (total structure weight) $\times$ (steel price value $-\mathrm{R} \$ 20.00 / \mathrm{kg}$ );

${ }^{2}$ annual electric energy revenue $=($ annual photovoltaic energy potential $) \times($ annual average $\mathrm{kWh}$ value $-\mathrm{R} \$ 0.587)$;

${ }^{3}$ time to pay the structure with the photovoltaic energy revenues = (total cost of the structure) $/($ revenue/12); and ${ }^{4}$ gross income in 30 years (excluding the structure value).

Figure 12 - Project option profiles \#5852

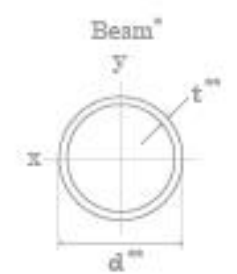

- Vallourec company profiles (2018)

*t value in millimeter

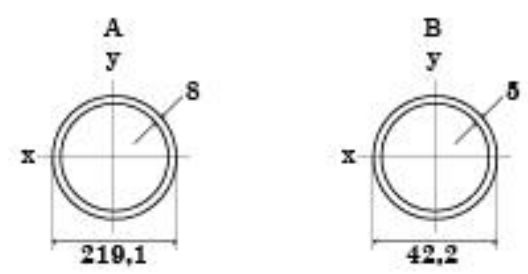

219,1
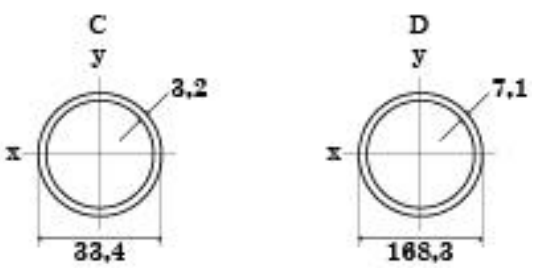

input: [ energy [kwh] weigth [kg]

Figure 13 - Design option \#5852 
Figure 14 - Project option profiles \#5808
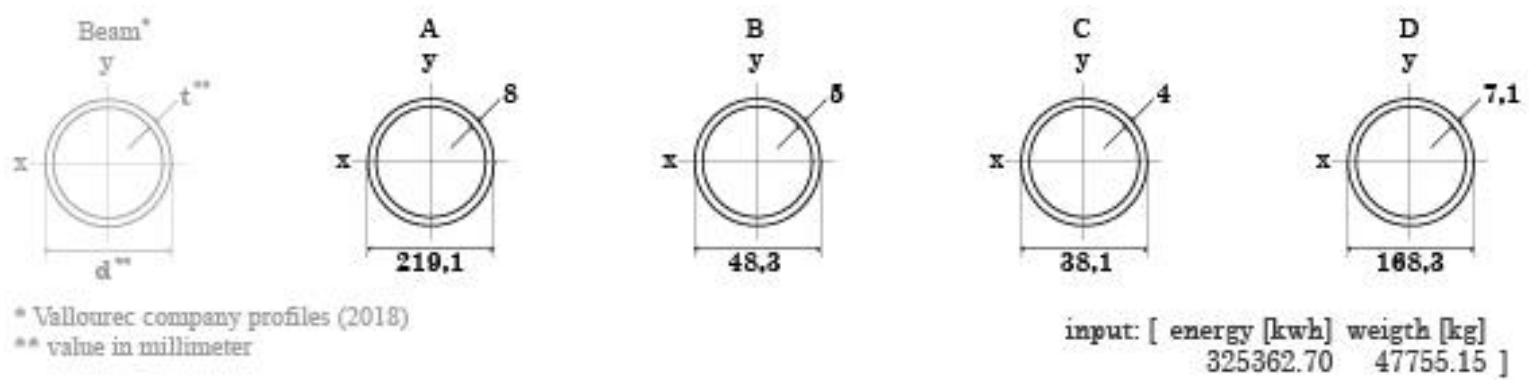

Figure 15 - Design option \#5808

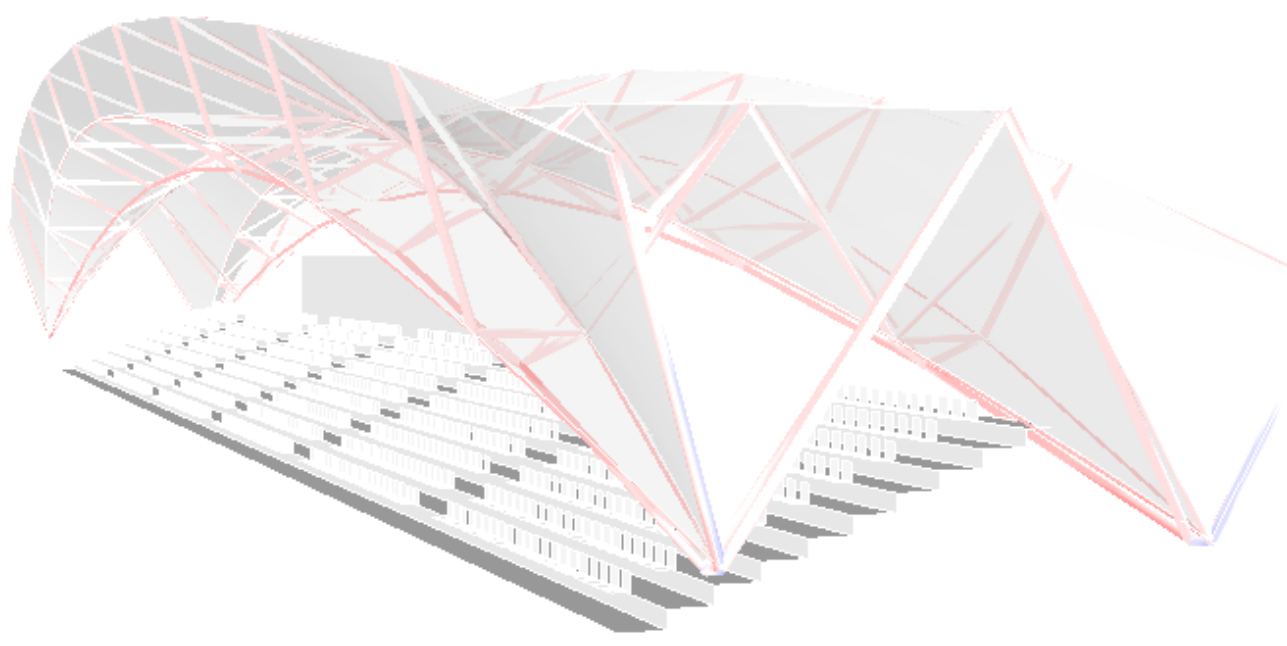

As these procedures have been used for a short time in the Brazilian context and are still in its infancy, we hope that this work offers support to architects in this design path. To do this, a detailed description of the strategies adopted in the application of the content in an architectural design of metallic construction was presented: in the description of the design of an architectural model with steel construction system; in the definition of a set of guidelines to assess the qualities of specific aspects of the product based on multiple variables - in the structural analysis of the roof and its capacity to generate photovoltaic energy -; in the approach of the modes of evaluation of generative processes with one or multiple objectives, through sampling and visualisation in a dispersion graph and in detailing the modes of evaluation of the resulting designs. It is considered that the process of formalising the problem presented here and the comparison of the two project optimisation scenarios performed are relevant in the contemporary context of architecture. However, we believe in a broader contribution to this investigation, by showing how different formulations for the same problem behave in a design process, especially in its initial phases of creative generation of the shape.

We also highlight the potential of using genetic algorithms as an auxiliary tool integrated with generative design and as a design method, allowing a customised application of scientific procedures (modelling) for the synthesis of form (final design). In the workflow presented here, a creative approach is overlaid to traditional, "hardcore" scientific methods.

It is, however, necessary to put the relevance of this project path into perspective, recognising it as a powerful resource available to professionals, but whose adequacy must necessarily be weighed according to the nature of the problem, criteria and restrictions placed at stake. In fact, it should be considered that this path does not completely break with the cognitive logic of traditional architectural design processes, being marked by some of its principles and characteristics. Here, the existence of specific cycles of analysis, synthesis and evaluation is highlighted, as described by Lawson (2011), although significantly streamlined over time and informed with greater accuracy as to various aspects of product performance.

Architectural production and its design processes are always marked by specific demands and conditions. Each solution is the result of many factors - knowledge, designer's skills, requirements and restrictions of 
different orders. From the initial moments of conception to the final solution proposed, there is usually intense work of optimisation along the design path, the result of continuous problematisation that feeds the reflection actions of the designer, which, in general, are not linear. In different ways, this marks the procedures studied here as well as the more conventional and recurrent practices. In the same way, the notions of imprecision, incompleteness and uncertainty, which are inherent to all design processes, impose the need to understand the limitations of each one and, also, the possible complementarity between them. (SCHÖN, 2000; LAWSON, 2011). In this light, tools and methods discussed here need to be thought of in their imaginable articulations with others, in all design stages.

Lawson (2011) claims that there is unlikely to be a correct or even optimal response in the design process. Thus, although the experiment developed here generated thousands of different project options, as the results were being analysed, it was clear how fragile the certainty of an assertive answer (solution) to a problem. This is because once a decision has been made, much of the scope for exploring possibilities in the later phases is limited, making it highly unlikely that the design process will achieve a truly "optimal" project.

In any case, the use of parametric tools to investigate the maximum number of design hypotheses from a set of variables stipulated beforehand allows the exploration and evaluation of complex situations that, in practical terms, would be impossible to cover manually. The importance of such tools is particularly evident in view of the complexity of contemporary demands, which demand from architects increasingly complex and difficult approaches to be covered in conventional methods. The research presented intends to inspire further research to investigate the use of genetic algorithms in other stages of the design processes or to investigate possibilities of their integration with other computational tools aimed at architectural production. It also raises countless research possibilities that associate variables related to the demands of sustainability, experiments with new materials and construction technologies, among others.

Finally, this study and the experiment developed present a transdisciplinary path for professional action. According to Brandão (2005), architecture is configured as transdisciplinary in its intrinsic constitution, as it places the built world, the world of ideas and the world of language in a reciprocal and interdependent function. Here, tools and method simultaneously enable and enhance the architect's transit through different areas of knowledge, namely to cover disciplines such as architecture, engineering, mathematics, informatics and biology. Notably, there was a great approximation of the first two, breaking some boundaries between them.

\section{References}

ALEXANDER, C. Ensayo sobre la síntesis de la forma. Buenos Aires: Ediciones Infinito, 1976.

ASHBY, W. R. Uma introdução à cibernética. São Paulo: Editora Perspectiva, 1970.

ASSOCIAÇÃO BRASILEIRA DE NORMAS TÉCNICAS. NBR 6123: forças devidas ao vento em edificações. Rio de Janeiro, 1988

ASSOCIAÇÃO BRASILEIRA DE NORMAS TÉCNICAS. NBR 8681: ações e segurança nas estruturas: procedimento. Rio de Janeiro, 2003

ASSOCIAÇÃO BRASILEIRA DE NORMAS TÉCNICAS. NBR 8800: projeto de estruturas de aço e de estruturas mistas de aço e concreto de edifícios. Rio de Janeiro, 2008

BARCZIK, G.; KRUSE, R. Shifting Design Work from Production to Evaluation: an evolutive design tool. In: eCAADe CONFERENCE, 34., Oulu, 2016. Proceedings [...] Oulu: University of Oulu, 2016.

BORGES, M. F.; GRILO, L. F.; FAKURY, R. H. Metodologia e validação de design estrutural baseado em desempenho para concepção de estrutura de torre eólica. Ambiente Construído, Porto Alegre, v. 16, n. 4, p. 93-108, out./dez. 2016.

BRANDÃO, C. A. L. A traduzibilidade dos conceitos entre o visível e o dizível. In: DOMINGUES, I. (org). Conhecimento e transdisciplinaridade II. Belo Horizonte: Editora UFMG, 2005.

BROADBENT, G. Metodologia del diseño Arquitectonico. Barcelona: Gustavo Gilli, 1971.

BUCHANAN, R. Wicked problems in design thinking. Design Issues, v. 8, n. 2, p. 5-21, spring 1992.

CAETANO, I. et al. Creativity Inspired by Analysis: an algorithmic design system for designing structurally feasible façades. In: RE: ANTHROPOCENE, DESIGN IN THE AGE OF HUMANS, Chulalongkorn, 2020. Proceedings [...] Chylalongkorn: Chulalongkorn University, 2020. 
CALIXTO, V.; CELANI, G. A literature review for space planning optimization using an evolutionary algorithm approach: 1992-2014. São Paulo: Blucher, 2015.

GLANVILLE, R. On being out of control. Lemende Systeme, v. 11, jan./fev. 2002.

LAWSON, B. Como arquitetos e designers pensam. São Paulo: Editora Oficina de Textos, 2011.

LEITÃO, A.; BRANCO, R. C.; CARDOSO, C. Algorithmic-Based Analysis: design and analysis in a multi back-end generative tool. In: INTERNATIONAL CONFERENCE OF THE ASSOCIATION FOR COMPUTER-AIDED ARCHITECTURAL DESIGN RESEARCH IN ASIA, 22., Suzhou, 2017. Proceedings [...] Suzhou, 2017.

NAGY, D. Generative design. 2018. Available: https://medium.com/generative-design. Access: 10 abr. 2020.

NAGY, D.; ZHAO, D.; BENJAMIN, D. Nature-based hybrid computational geometry system for optimizing component structure. In: DE RYCKE, K. et al. (ed.). Humanizing digital reality. Singapore: Springer, 2018.

OXMAN, R. Theory and design in the first digital age. Design Studies, v. 27, p. 229-265, 2006.

PREISINGER, C. Karamba: user manual for version 1.2.2. 2016. Available:

https://web.arch.virginia.edu/ km6e/arch721/docs/Karamba_1_2_2_Manual.pdf. Access: 8 jun. 2021.

SAVOV, A. Digital design in architecture: research landscape map 1975-2019, CC BY-NC-SA 4.0.

Available: www.github.com/antonsavov/research-maps. Access: 29 out. 2020.

SCHÖN, D. A. Educando o profissional reflexivo: um novo design para o ensino e a aprendizagem. Porto Alegre: Artes Médicas Sul, 2000.

SHIFFMAN, D. The nature of code. California: Magic Book Project, 2012.

SPASIC, D. Ladybug Photovoltaics components released. Grasshopper3d, 2015. Available: https://www.grasshopper3d.com/forum/topics/ladybug-photovoltaics-componentsreleased?groupUrl=ladybug\&groupId=2985220\%3AGroup\%3A658987\&id=2985220\%3ATopic\%3A13095 23\&page $=4 \#$ comments. Access: 10 abr. 2020.

VASSÃO, C. A. Metadesign: ferramentas, estratégicas e ética para a complexidade. São Paulo: Blücher, 2010.

WIRSANSKY, E. Hands-on genetic algorithms with Python: applying genetic algorithms to solve realworld deep learning and artificial intelligence problems. Birmingham: Packt Publishing, 2020.

YANG, X.-S. Nature-inspired metaheuristic algorithms. $2^{\text {nd }}$. ed. London: Luniver Press, 2010.

YENIAY, Ö. Penalty function methods for constrained optimization with genetic algorithms. Mathematical and Computational Applications, Beytepe, v. 10, p. 45-56, 2005. 


\section{Renato Godoi da Cruz}

Departamento de Engenharia Civil | Universidade Federal de Ouro Preto | Campus Morro do Cruzeiro, s/n | Ouro Preto - MG - Brasil | CEP 35400-000 | Tel.: (19) 99716-5302 | E-mail: renatogcruz@hotmail.com

\section{Cláudia Maria Arcipreste}

Departamento de Arquitetura e Urbanismo | Universidade Federal de Ouro Preto | Tel.: (31) 3559-1484 | E-mail:

claudiaarcipreste@ufop.edu.br

\section{Rafael Lemieszek Pinheiro}

Programa de Pós-Graduação em Arquitetura e Urbanismo, Escola de Arquitetura | Universidade Federal de Minas Gerais | Rua Paraíba, 697 | Belo Horizonte - MG - Brasil | CEP 30130-141 | Tel: (31) 3409-8839 | E-mail: lemieszek@gmail.com

\section{Rovadávia Aline de Jesus Ribas}

Departamento de Engenharia Civil | Universidade Federal de Ouro Preto | Tel.: (31) 3559-1484 | E-mail: roviaaline@gmail.com

\section{Ambiente Construído}

Revista da Associação Nacional de Tecnologia do Ambiente Construído Av. Osvaldo Aranha, $99-3^{\circ}$ andar, Centro

Porto Alegre - RS - Brasil

$$
\text { CEP } 90035-190
$$

Telefone: +55 (51) 3308-4084

www.seer.ufrgs.br/ambienteconstruido www.scielo.br/ac

E-mail: ambienteconstruido@ufrgs.br

This is an open-access article distributed under the terms of the Creative Commons Attribution License. 